\title{
QUALITY PARAMETERS IN CONSERVATION-RESTORATION CHOICES - THE CASE OF THE TOWER OF THE WINDS IN ATHENS
}

\section{PAPADOPOULOU Maria ${ }^{1}$ GAZI Andromache ${ }^{2}$}

\footnotetext{
${ }^{1}$ Conservator-Restorer at Greek Ministry of Culture, BA, Conservation/Restoration of Antiquities \& Works of Art, MA, Cultural Management; mapapad23@yahoo.gr https://orcid.org/0000-0003-1684-4104

${ }^{2}$ Associate professor of museum studies, Dept. of Communication, Media and Culture, Panteion University of Social and Political Sciences; agazi@otenet.gr https://orcid.org/0000-0003-0882-8876
}

ABSTRACT: The chemistry- and physics-based approach of conservation has led to the view that conservator-restorers use quantitative criteria which provide objective choices. Today, however, there is a shift of focus from material-centred to people-oriented approaches within the field of heritage preservation. This shift leads to a redefinition of the conservation-restoration field and its ethics in relation to society and calls for the adoption of diverse methodologies. Within this context, this paper discusses the qualitative factors which inform decision-making processes in conservation-restoration practice. More specifically, the paper examines the case of the so called "Tower of the Winds" in Athens and looks at the quality parameters which informed conservation-restoration work carried out at the Tower during 2014-2015. Overall, it is shown that the prominence of the quality parameters which inform contemporary conservation-restoration practice reveals the subjective dimension of conservation-restoration choices. The research has also showed that current trends tend to emphasize the historical rather than the aesthetic or other values of monuments.

KEYWORDS: Conservation/restoration, quality parameters in decision-making, Tower of the Winds, Athens

\section{Introduction}

The view of conservation-restoration as a scientific discipline based on chemistry and physics, which prevailed during the $20^{\text {th }}$ century, has led to the notion that conservators use quantitative criteria which are indicated by the physico-chemical properties of materials, and therefore provide "objective" choices (Muñoz Viñas, 2005). Today, however, there is a shift from material-centred to people-oriented approaches within the field of heritage preservation. This shift, which is in line with the anthropo- 
centric turn in cultural heritage management at large, leads to a redefinition of the conservationrestoration field and its ethics in relation to society (Avrami, 2009) and calls for the adoption of diverse methodologies which may greatly benefit from the toolkit of social and cultural studies (museum studies included).

Within this context, and as part of a larger study on the role of conservation in the interpretation of monuments (Papadopoulou, 2017), this paper discusses the qualitative factors which inform decisionmaking processes in conservation-restoration practice. More specifically, the paper examines the case of the Horologion of Andronikos of Kyrrhos (also known as the Tower of the Winds) in Athens ${ }^{1}$ (Fig. 1), as an example of a monument with a long history in the application of conservation-restoration practices from the $19^{\text {th }}$ century to date (EACA, 2016). The Tower of the Winds (henceforth the Tower) is a unique architectural monument, which is preserved intact, and stands as a landmark for an entire area in the old city centre, known widely as "Aerides” (Winds).

After a brief introduction to the monument's history, the paper presents the main research questions and the methodology used and discusses how they were applied to the conservation-restoration work at the Tower.

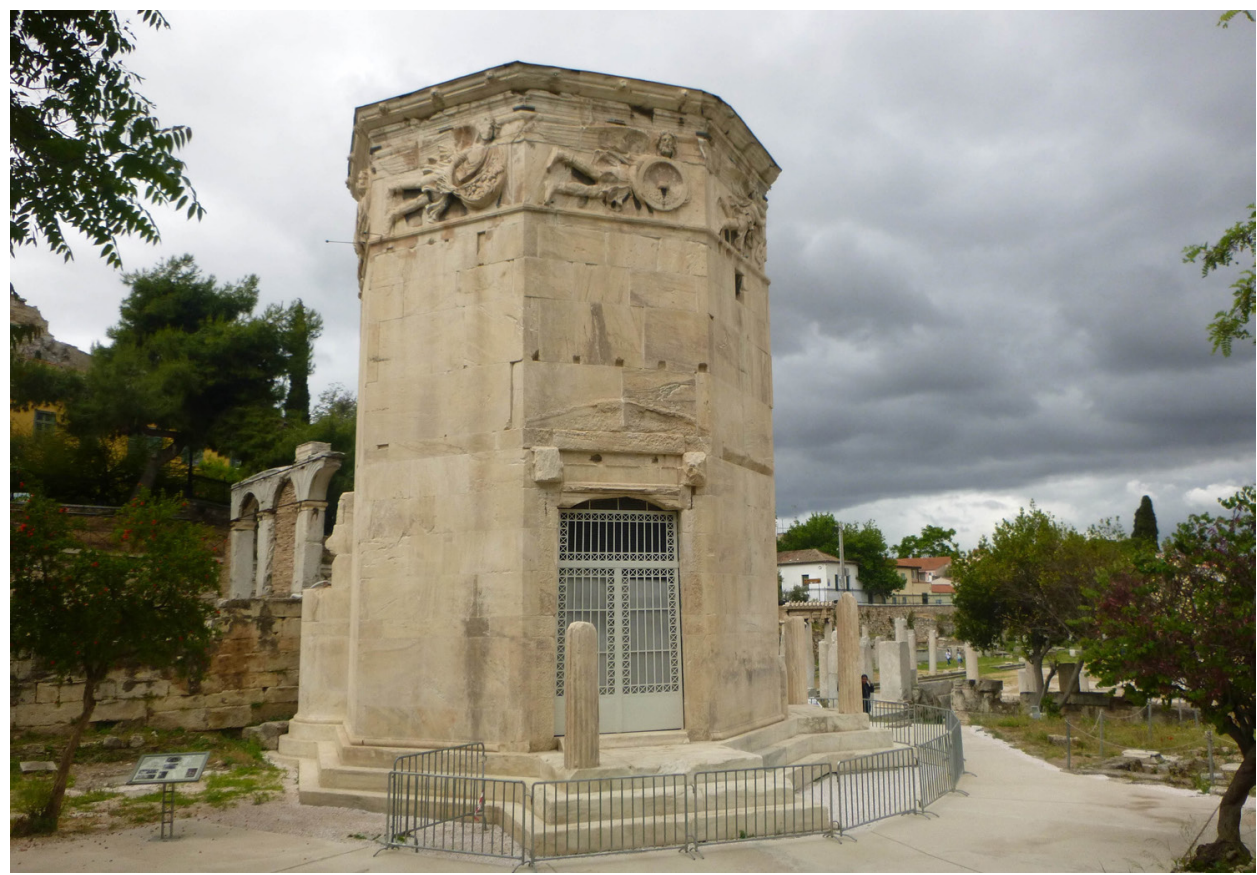

Fig. 1 The Tower of the Winds, Athens (photo credit: Greek Ministry of Culture \& Sports - Fund of the Archaeological Proceeds) 


\section{The Tower of the Winds ${ }^{2}$}

The Tower is located under the northern slope of the Acropolis, within the Roman Agora of Athens. It has a 2,000-year long biography, in which diverse cultural groups succeeded one another, while its original operation still puzzles scientists today. The 14-metres-tall Tower was built most probably at the end of the $2^{\text {nd }}$ century BC by the architect and astronomer Andronikos of Kyrrhos. The octagonal monument is made entirely of Pentelic marble except for the foundations ${ }^{3}$ (EACA, 2016). Atop its fully preserved roof rests a Corinthian capital which possibly served as the base of a bronze wind vane in the form of sea god Triton. Beneath the roof is a frieze bearing the personifications of the eight wind deities, which are depicted in high relief. Further below, incised lines form an equal number of sundials on the exterior of each side of the building. To the best of our knowledge, a hydraulic mechanism operating in the interior of the building, powered a water-clock or a 'planetarium' device (Noble \& de Solla Price, 1968). Nothing of the original mechanism survives. ${ }^{4}$

During the Byzantine period, and even after the fall of Athens to the Ottomans in the $15^{\text {th }}$ century, the monument served as a Christian church. In the late period of the city's Ottoman occupation, the building was also used as a tekke (meeting place) of the Mevlevi order (a Sufi order also known as the Whirling Dervishes). In 1838-1839, that is after the foundation of the modern Greek state, the monument (which was by that time partly buried) was unearthed in its entirety during excavations by the Archaeological Society at Athens. In the years that followed, there were sporadic and undocumented interventions in the monument. In 1845, for example, an attempt to reconstruct the sundials led to the installation of new metal gnomons. Later conservation work was primarily targeted at consolidating the roof and the exterior of the Tower. ${ }^{5}$ The interior of the monument attracted very limited interest and was until recently used as a warehouse for scattered finds (Papastamatiou \& Fotopoulou, 2011). An extensive programme of conservation-restoration work funded by the National Strategic Reference Framework 2007-2013 was carried out during 2014-2015. Several multidisciplinary teams were employed in the project, while its management was entrusted to a scientific committee consisting of two conservators, one archaeologist, one architect and one civil engineer. Priorities included securing the monument's preservation, saving any surviving historical information, and making the monument available to researchers and the public (EACA, 2016).

\section{Research questions, methodology and results}

Basic research questions included why, how, who and for whom we conserve. Our work aimed at an indepth study of the decision-making processes which informed conservation-restoration work carried out at the Tower during 2014-2015 and included archival research and semi-structured in-depth

\footnotetext{
2 For more information see http://efaathculture.gr/wp-content/uploads/2016/05/THE-CONSERVATION-ANDVALORIZATION-OF-THE-HOROLOGON-OF-ANDRONIKOS-OF-KYRRHOS.pdf.

3 Which are built of a kind of porous stone.

4 For a comprehensive history of the monument see Kienast 2008 and 2013; Webb 2017. See also Robinson 1943.

5 The most extensive and systematic interventions took place during 1915-19 by architect and archaeologist Anastasios Orlandos and in 1976 when the Greek Archaeological Service conducted consolidation and conservation work under the supervision of archaeologist Maria Brouskari.
} 
interviews with two conservator-restorers and the archaeologist involved in these interventions. ${ }^{6}$ In addition, a small pilot visitors' study was carried out for understanding the impact of conservation treatments on the public's perception of the monument. According to the key research questions referred to above, the main results of the study are as follows.

\subsection{Why do we conserve?}

Conservation-restoration's primary aim is to preserve monuments. While preserving monuments' materiality, however, conservation-restoration also helps disseminate their perceived "significance" for the present and future generations (Caple, 2009). Obviously, the "significance" or "value" that each era attributes to specific monuments guides the decision-making process. In the late $20^{\text {th }}$ century, for example, emphasis was placed on the educational function and the historical value of monuments, a trend which has led in recent years to the emergence of conservation-restoration as a tool for studying monuments. Today, however, one important motive for conservation-restoration is to make monuments accessible to the public. As the head conservator at the Tower put it: "Conservationrestoration enters the zone of studying monuments." Visitors on the other hand reported that the aim of conservation-restoration is: "To keep history alive for future generations" or "to preserve and understand past experiences, skills and beliefs".

Treating decay is another strong motive for undertaking conservation work, in cases where decay is causing undesirable alteration (considered as "damage" in the eyes of the public) ${ }^{7}$. Today there is a growing awareness that damage reflects a monument's history and environment. So, when is damage considered undesirable? During the latest interventions in the Tower, decay was considered undesirable when it threatened the monument's preservation, especially its stability.

Another reason behind conservation-restoration is to "control" time. Conservator-restorers' attitude towards the traces of time range from an effort to cover them up to their highlighting. It is now widely accepted that the cultural biography of monuments is their most important attribute, while the notion of reversibility and the return to a supposedly "original" state is a rather arrogant attitude (Smith, 1989). But, even though the signs of time are considered valuable today, there is still a tendency to „freeze” time at a specific juncture (Tournikiotis, 2010), thus limiting any potential messages that each consecutive era may add to the monument in question. During the 2014-15 interventions in the Tower all traces of the monument's history were respected if they were not considered a threat to the monument's preservation, in which case they would be seen as an undesirable alteration.

6 Due to time constraints interviews with other stakeholders were not included, while the architect and the civil engineer who were members of the scientific committee were not available.

Decay is any chemical or physical modification of the intrinsic stone properties leading to a loss of value or to the impairment of use, while damage is the human perception of the loss of value due to decay (ICOMOS-ISCS, 2008, p. 8). 


\subsection{How do we (decide what to) conserve?}

An important question examined was the relationship between conservation-restoration and the documentation of monuments, and how this relationship affects decision-making processes. The contribution of conservation-restoration in exploring a monument's cultural biography is acknowledged (Berducou, 1996, Philippot, 1996). At the same time, however, care must be taken to ensure access to information for future generations, bearing in mind that sometimes the revelation of certain information may require the sacrifice of latent others (Ashley-Smith, 2009). In the Tower's case, meticulous documentation and keeping conservation records was a priority, while interdisciplinary collaboration helped to improve research and recording techniques.

For example, the latest interventions confirmed the Christian use of the monument, but also revealed traces of ancient decoration:

"Conservation-restoration may help uncover unknown facets of the monuments [...] Byzantine frescoes [...] definitively confirmed the use of the monument as a church." (Head archaeologist)

"The mere fact that conservation-restoration begins, helps the study of the monument. Sometimes you can read the monument only in such close contact [...] And the monument has always different things to say. And it doesn't stop here, because we don't know what the conservation-restoration of the same monument will give to researchers and conservators who will follow." (Wall painting conservator)

We also examined decision-making processes which guided cleaning treatments. Cleaning is a common intervention, despite its being a non-reversible procedure. Cleaning cannot be described as an „interpretive neutral process”, as it is a conscious choice to remove or maintain certain elements (Eastop \& Brooks, 1996 in Caple, 2000, p. 99). But, which reasons indicate the need for cleaning nowadays? It seems that while conservation aims to not visually affect monuments, a cleaned surface demonstrates care for monuments to the lay public (Caple, 2000). In the Tower's case, for example, cleaning was carried out mainly where it was considered vital for the preservation of the monument or because it served documentation purposes. But, the decision not to remove the black crusts (Fig. 2), despite the concerns (mainly expressed by archaeologists) that this might be associated with the Archaeological Service's inability to take care of the monument, caused controversy. In the words of the head conservator:

"[We had] to convince the rest of the group that the monument will remain 'dirty'. The [opposite] argument was that [...] people would think [...] we did not do our job properly."

Overall, the evidence from this study suggests that the pursuit of a monument's original image or aesthetic unity have decreased as arguments towards cleaning. 


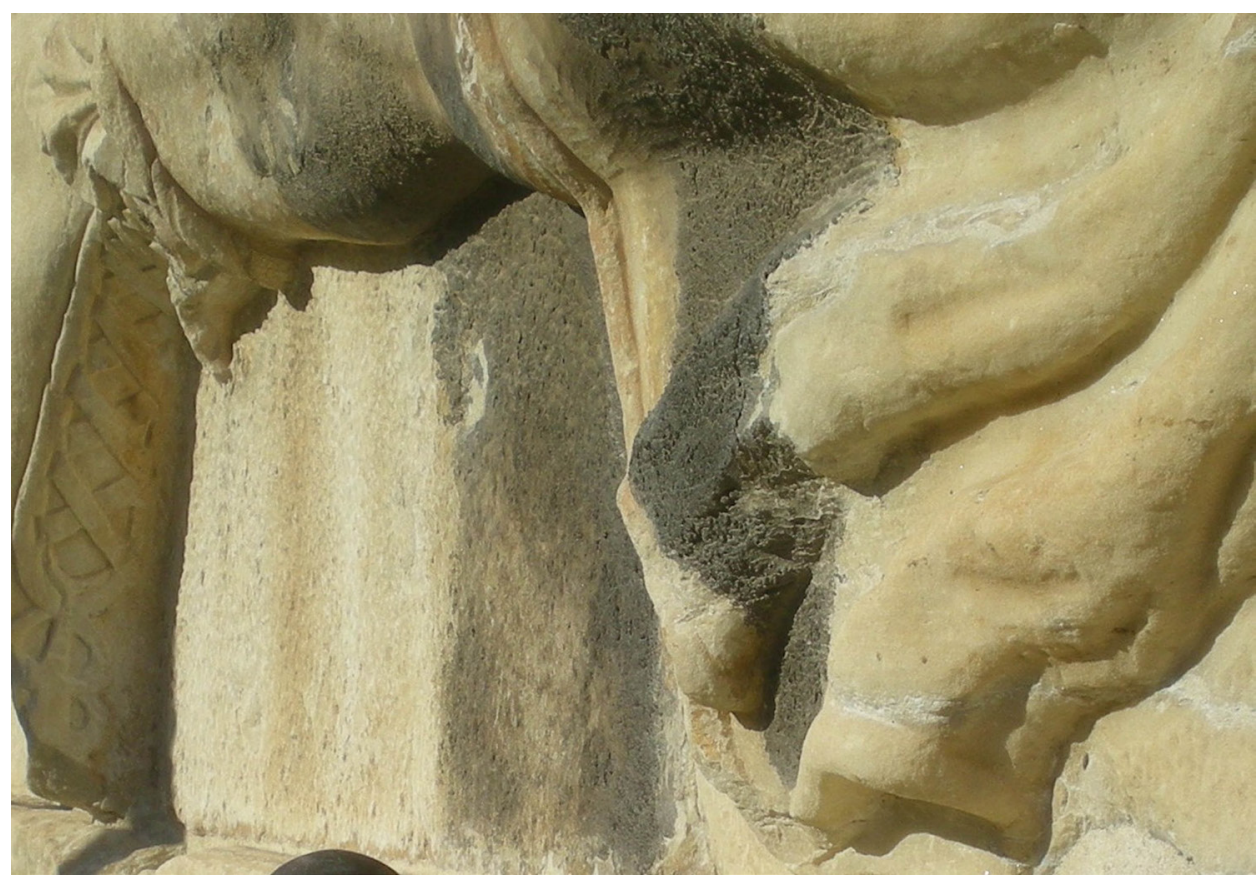

Fig. 2 Black crusts on the Tower's frieze, Tower of the Winds (photo credit: Greek Ministry of Culture \& Sports - Fund of the Archaeological Proceeds)

Then came the question of how we deal with loss of material. The quest for integrity and aesthetic unity which had prevailed in the past led to "creative reconstructions" which produced interpretations revealing more about the context within which they occurred, than about the original image of the monuments conserved and restored (Walden, 1985). In order to moderate such interpretive propositions, contemporary conservation ethics suggest the search for equilibrium among the aesthetic, the historical and the physical properties of monuments (ECCO, 2003, Article 5). But, how can such an equilibrium be achieved? In the Tower's case, the 2014-15 interventions are indicative of a tendency to limit the addition of materials to what is absolutely necessary for the protection of the monument, serving functional rather than aesthetic needs. This approach is in line with the principle of minimal intervention.

However, we often face dilemmas about balancing conservation ethics with demands regarding the educational and communicative role of monuments. Innovative technologies such as virtual methods of presentation, for example, have been used as a solution to this problem, as they offer visitors visual interpretation which does not depend on the addition of materials. But, as many scholars note (e.g. Hodder et al., 1995 in Georgaki, 2012), these visual aids may sometimes demote the „intellectual process of filling the gap", which contributes to the understanding of an object. 


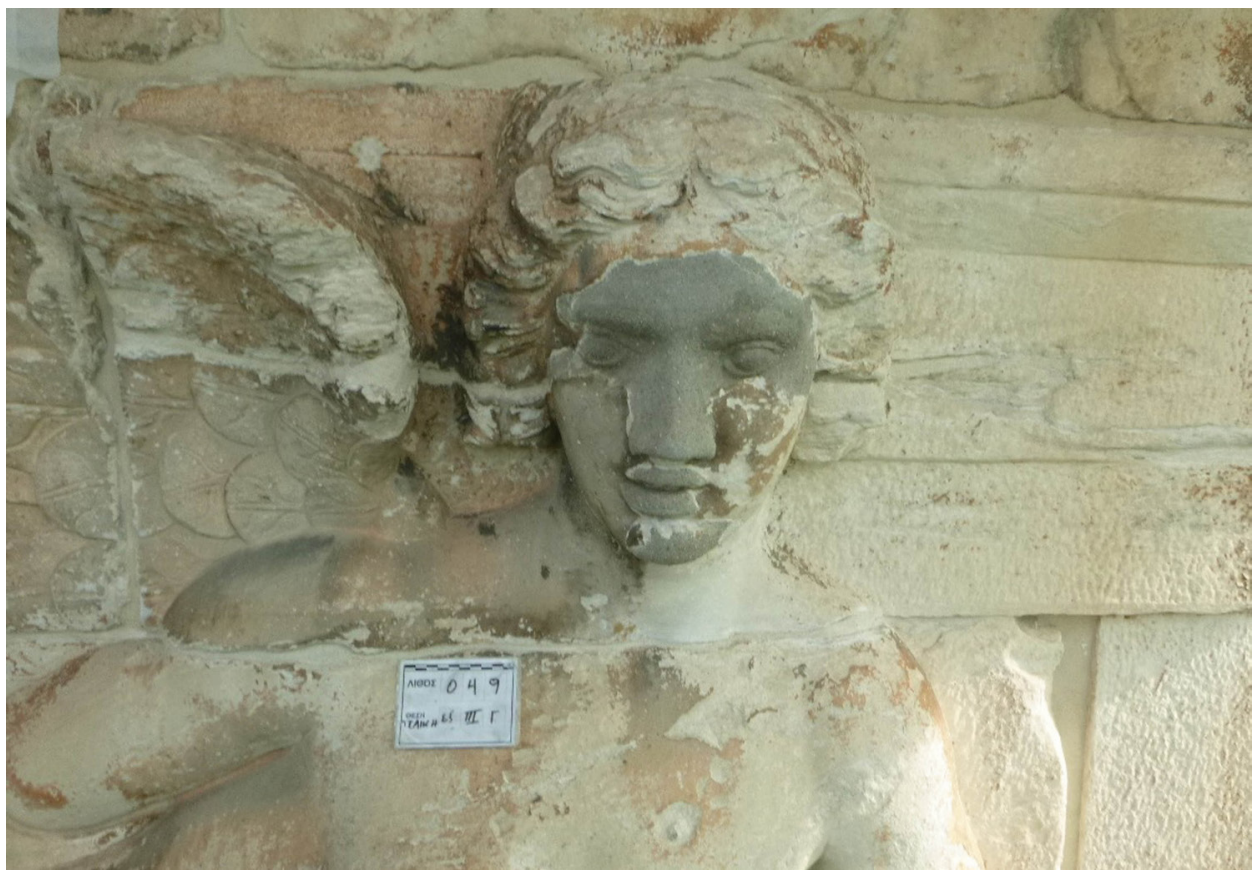

Fig. 3 Zephyros (West wind), past intervention, Tower of the Winds (photo credit: Greek Ministry of Culture \& Sports - Fund of the Archaeological Proceeds)

We further studied attitudes towards different historical phases and previous conservationrestoration interventions. As stated in the Charter of Venice (ICOMOS, 1964, Article 11), "remarkable additions" should be preserved and their removal "can only be justified in exceptional circumstances", following a collective decision taken by a multidisciplinary team. But, the identification of "remarkable additions" involves subjective criteria. In the Tower's case, this became clear in the debate about an "addition" on the face of the wind Zephyros (which does not serve functional needs) (Fig. 3). In the end, and after consultation with other scientists, the view in favour of preservation prevailed. The different views expressed on the matter are elucidating:

"I take as an example the wind Zephyros, the face of which had been filled [previously] with cement mortar. This filling was conserved and maintained although not all of us agreed [...] I believe that it ought to be removed [...] as it was done with cement mortar [...] which, in my view, is a non-compatible material. This was an unnecessary intervention." (Head archaeologist)

"[...] the full face [of Zephyros] was erased. In the bibliography, however, it is known with this past intervention which is quite good and must have been the result of study [...] For this reason and because we didn't know when the addition was placed, we decided to keep it." (Head conservator)

"As for the lionheads [there is an addition on one of them; Fig. 4] it could be argued that this [addition] serves a functional purpose, [that is] better drainage of rainwater from the monument's roof [...]. This could have been removed too and be replaced with a new one, but since it serves a functional need no question of its removal was raised." (Head archaeologist). 


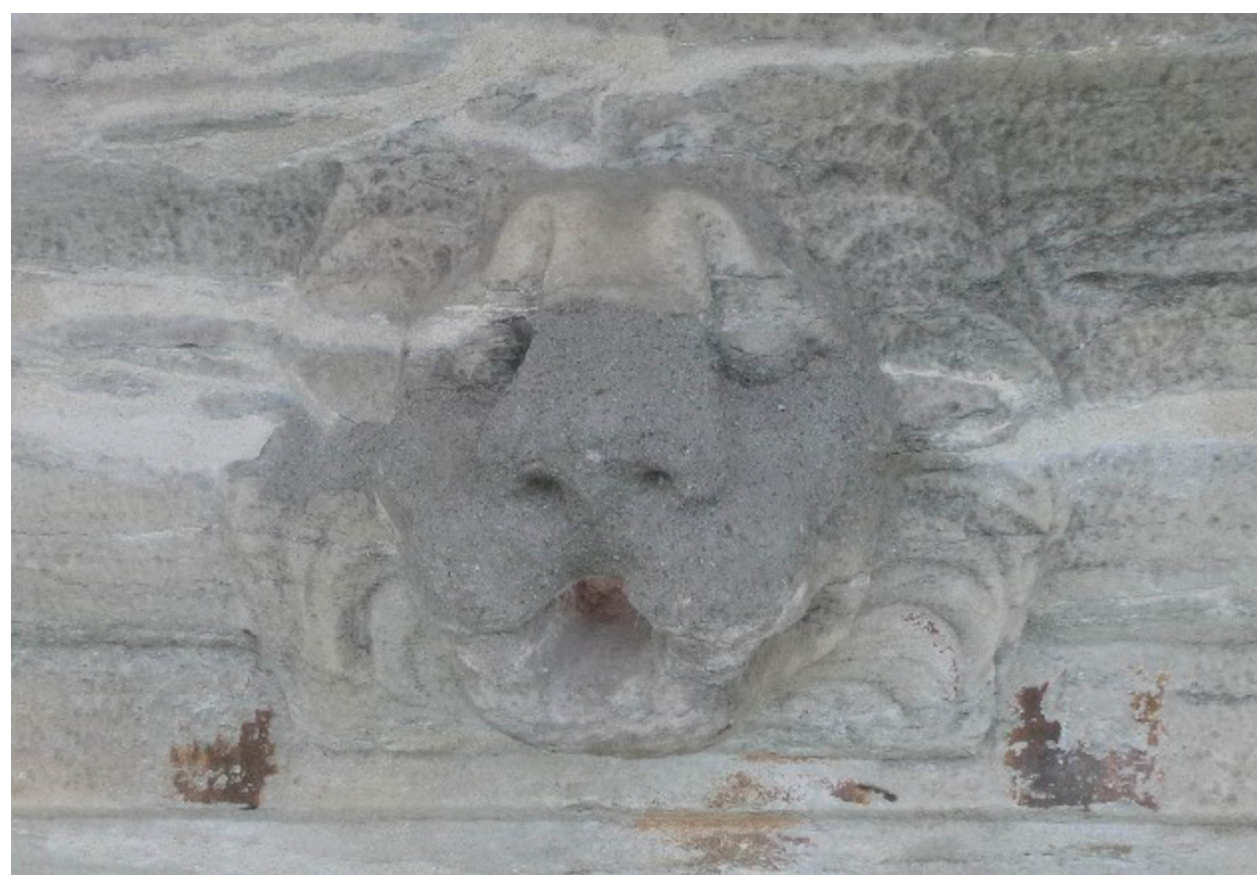

Fig. 4 Preservation of a lion's-head addition which helps rainwater drainage from the roof, Tower of the Winds (photo credit: Greek Ministry of Culture \& Sports - Fund of the Archaeological Proceeds)

Overall, functional needs seem to be rated as more important than aesthetic ones. We could suggest that the preservation of older additions provides a middle ground between current trends that discourage reconstruction and demands for readability and stability. This attitude is in line with the principle of minimal intervention while it also recognises the historical significance of older additions. This view is reinforced by the argument that removal could cause further damage.

However, although the preservation of the Tower's current state was a priority, the desire to provide evidence for the interpretation of the monument to the public meant that choices had to be made occasionally about traces dating to different historical phases. Figures 5 and 6 , for example, show a slab where it was decided to remove a plain and largely loose Ottoman coating to reveal traces of painting which confirmed the Christian use of the monument. Overall, however,

"all phases of the monument were respected, including $19^{\text {th }}$ century graffiti, visible at the lower part of the building's interior." (Wall painting conservator) 

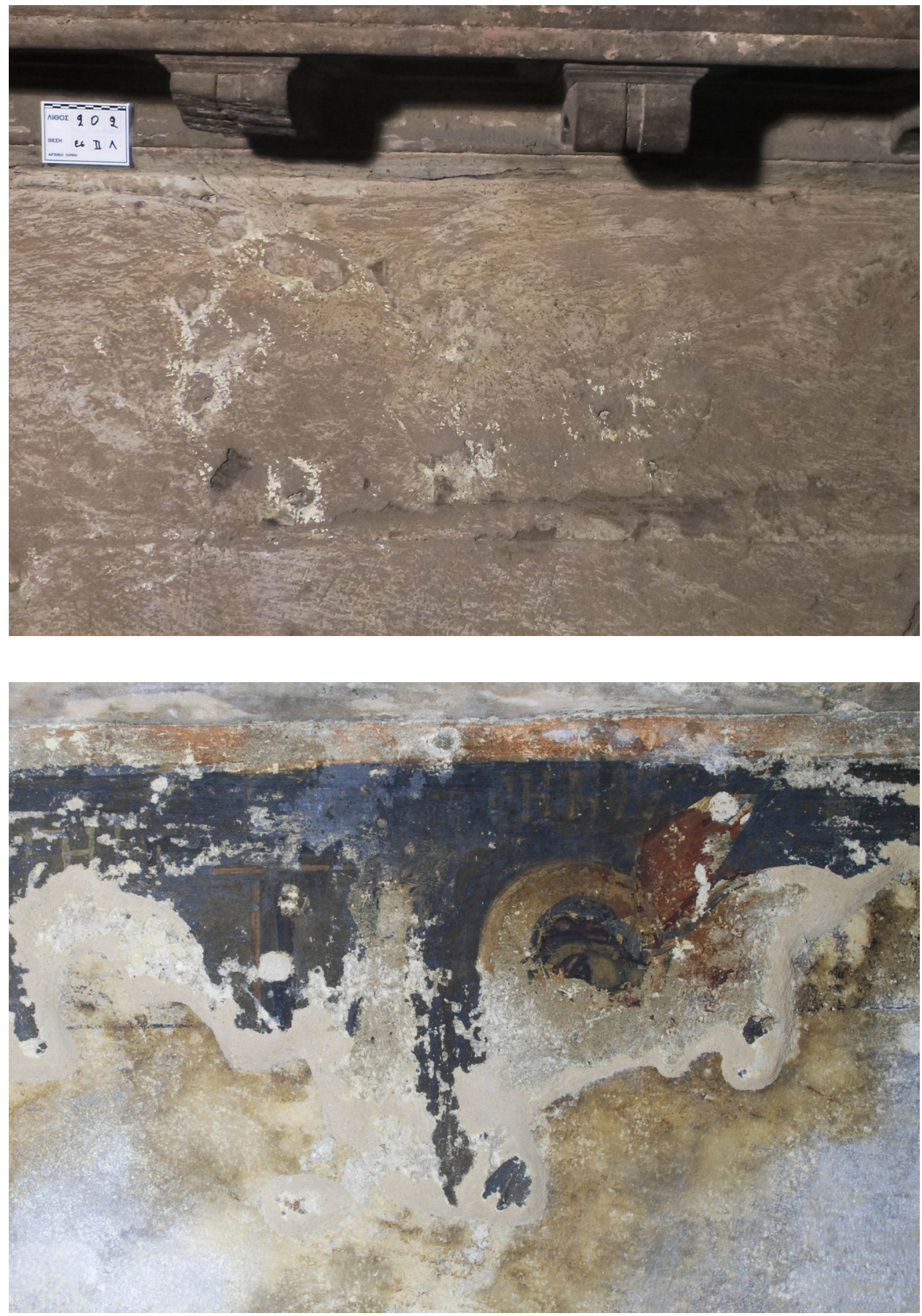

Fig. 5 and 6 Ottoman vs Christian traces of paint and coatings: searching for evidence to solve issues of interpretation, Tower of the Winds (photo credit: Greek Ministry of Culture \& Sports - Fund of the Archaeological Proceeds) 


\subsection{Who conserves/decides?}

We already referred to the interdisciplinary team which worked at the Tower and to some of the debates that occurred. But, how effective can communication be within an interdisciplinary team? How are tensions resolved? And, who is responsible for the final decisions?

Decisions about conservation-restoration were the result of a dialogue in which all members of the team participated. Cooperation with other bodies and scientists was welcome and helped to resolve disagreement: ${ }^{8}$

"A work of this scale requires collaboration. There were engineers, topographers, manual workers, conservators. I think we all gained from this [...]" (Head conservator) "To me this particular project was a very positive experience as I had the chance to collaborate with colleagues from different disciplines and improve my [sense of] coexistence with other fields [...] I believe that collaboration was fruitful. All decisions were taken after exhaustive discussion and any disagreements were resolved with the monument's benefit in mind." (Head archaeologist)

But, despite the high degree of satisfaction reported, there were still some hierarchy issues among different specialists. It is true that conservation-restoration professionals in Greece are still struggling to distinct themselves from other heritage professions and establish their scientific status and professional rights. This is particularly acute as professions involving manual activities are still illrecognised in the country. All the above lead to a certain lack of confidence on the part of conservatorrestorers, low status in the hierarchy and obstacles to the diffusion of knowledge and communication among different professionals in the heritage management field at large (Brooks, 2013).

\subsection{For whom do we conserve?}

Conservator-restorers are expected to preserve cultural heritage for both the present and future generations (ECCO, 2002). Within this context, making monuments accessible to wider audiences is an important motive for conservation-restoration practices. In the Tower's case, "Making the monument accessible to the public for the first time was a priority from the beginning" (Head archaeologist) something that was valued by visitors ("I appreciate that we can go inside the Tower").

Apart from facilitating physical accessibility, it is also crucial to ensure a monument's readability by visitors. In the Tower's case, it seems that conservation-restoration work has succeeded in making the monument comprehensible: "I like the Tower because it is well preserved and therefore understandable. Not just a bunch of stones" (Visitor). Yet, extreme caution is required when considering the best possible conservation-restoration techniques, as sometimes a specific intervention can make one historical phase stand out as more "readable" than others, thus obstructing visitors' ability to recognise these phases (Ashley-Smith, 2009). In fact, deciphering the degree of conservation-restoration puzzled several visitors to the Tower:

8 Overall control of the project, however, lied with the relevant bodies of the Greek Ministry of Culture, which had to approve all plans submitted by the conservation team. 
"I always wonder what is original and what is added due to conservation"; "how do you recognize the interventions?";

"how much of the monument has been reconstructed?"

It should here be noted that, although conservator-restorers participate increasingly in activities which aim at communicating and interpreting their interventions to the public, such activities are limited, and are usually done occasionally on the margin of their main professional duties. According to many in the field, however, collaboration among heritage professionals with diverse backgrounds is essential in order to enhance visitors' understanding of monuments (Mertzani, 2008, Spantidaki, 2005). This is even more crucial as many heritage professionals do not have a clear view or understanding of the public's expectations on conservation-restoration (Pye, 2001, H. Jones, 2002, Williams, 2013). ${ }^{9}$

\section{Discussion}

\subsection{Subjectivity and conservation ethics}

The discussion so far has revealed the subjective dimension of conservation-restoration choices. No decision, non-intervention included, is neutral, as all decisions are interpretive propositions (Muñoz Viñas, 2005, Smith, 1989, Villers, 2004). Fundamental principles of conservation-restoration such as minimal intervention and reversibility, are subjectively interpreted in order to balance the positive and negative effects and justify decisions (Melucco Vaccaro, 1996, Marçal, Macedo \& Duarte 2014). In the Tower's case, for example, where the emphasis was placed on adhering to conservation ethics, minimum intervention had to ensure certain conditions, such as guaranteeing the preservation of the monument, research and documentation needs and facilitating public access.

Regarding the concepts of authenticity and the "one and only true nature", contemporary approaches (e.g. The Nara Document on Authenticity, ICOMOS, 1994) encourage the view that monuments have a rich, multifaceted, cultural biography (M. Jones, 1994, Ashley-Smith, 2009). The quest for a monument's ,true nature" is simply a fallacy as any choices leading to highlighting a certain "truth" is at the expense of other possible "truths" that may co-exist in the monument (Muñoz Viñas, 2005). According to the criteria of our time, if interventions do not mislead, they are not considered to affect the authenticity of monuments (Kemp, 2009). Our study has showed that since the preservation of all messages that a monument bears is practically impossible (Muñoz Viñas, 2005, McClure, 2013), current conservation-restoration trends emphasise a monument's historical rather than aesthetic or other values.

\subsection{Context}

Overall, it has been shown that the prominence of the quality parameters which inform contemporary conservation-restoration practices reveals that our choices are shaped by (and reflect) the sociopolitical and ideological context of our time. Understanding the parameters which shape this context

9 In the Tower's case, for example, the results of the pilot visitors' study showed that the concerns of the scientific committee that the degree of cleaning and the equipment placed to protect the monument would disturb visitors were unsubstantiated. 
is a key factor in evaluating interventions and making decisions.

\section{Challenges and prospects}

It is widely accepted today that the field of heritage conservation-restoration should be redefined in relation to contemporary society and current needs (e.g. Clavir, 2009, Cane, 2009, Matero, 2000, Richmond \& Bracker, 2009). This presents conservation-restoration professionals with new challenges. First, the growing recognition of subjectivity in conservation-restoration practice means the acceptance of the occasional "faulty" decision but generates further research and critical thinking. Self-criticism is a painful process, but it is in the interest of the field as it leads to greater self-awareness and self-confidence. Furthermore, if we think of monuments as human cultural creations "rather that the product of measurement, analysis and chronological order" (Hölling, 2017, p. 4), then it is necessary to broaden the theoretical grounding of our field by introducing methodologies from the humanities and the social sciences. Today a competent conservation-restoration professional must combine successfully technical, scientific and artistic skills, coupled with effective communication and organisational abilities (Muñoz Viñas, 2005, Brooks, 2013). In addition, there is a need to explore the role of conservation-restoration in the sustainable management of cultural heritage. Let us not forget that the mere concept of sustainability is in line with the principles of conservation-restoration, as it embraces respect for the needs of the present and future generations (Brooks, 2013). As for the inclusion of diverse perspectives in conservation-restoration decisions, there is a need for a meaningful and equal dialogue among scientists and society at large. Last, but not least, understanding visitors' perceptions could be a critical factor in decision-making processes in conservation-restoration practice, and could enhance the view of conservation-restoration as an interpretive and educational tool.

In brief, conservation-restoration theories and ethics which developed during the $20^{\text {th }}$ century to limit the arbitrariness of interventions and give scientific status to the field still prevail in the application of conservation-restoration methods. But, as social needs related to the meaning of heritage in contemporary society change, the need for revising some fundamental conservation-restoration principles becomes evident. So, while still considering conservation ethics as formulated during the $20^{\text {th }}$ century, we should also - and perhaps more importantly - realise the social impact of our choices and contemplate on the needs of the $21^{\text {st }}$ century and beyond.

\section{Acknowledgements}

Many thanks are due to the Direction and personnel of the Ephorate of Antiquities of the City of Athens for granting the necessary permissions and facilitating our research, to the Ephorate's staff who agreed to be interviewed and to all those who took part in the visitors' pilot study. 


\section{Bibliography}

Ashley-Smith, J. (2009). The basis of conservation ethics. In A. Richmond \& A. Bracker (Eds.), Conservation: principles, dilemmas and uncomfortable truths (pp. 6-24). London: Routledge.

Avrami, E. (2009). Heritage, Values, and Sustainability. In A. Richmond \& A. Bracker (Eds.), Conservation: principles, dilemmas and uncomfortable truths (pp. 177-183). London: Routledge.

Berducou, M. (1996). Introduction to archaeological conservation. In N. Stanley-Price, M. Kirby Talley \& A. Melucco Vaccaro (Eds.), Historical and Philosophical Issues in the Conservation of Cultural Heritage (pp. 248-259). Los Angeles: Getty Conservation Institute.

Brooks, M. (2013). Culture and anarchy: considering conservation. In E. Williams (Ed.), The Public Face of Conservation (pp. 1-7). London: Archetype Publications.

Cane, S. (2009). Why Do We Conserve? Developing Understanding of Conservation as a Cultural Construct. In A. Richmond \& A. Bracker (Eds.), Conservation: principles, dilemmas and uncomfortable truths (pp. 163-176). London: Routledge.

Caple, Chr. (2000). Conservation Skills: Judgement, Method and Decision Making. London: Routledge. Clavir, M. (2009). Conservation and Cultural Significance. In A. Richmond \& A. Bracker (Eds.), Conservation: principles, dilemmas and uncomfortable truths (pp. 139-149). London: Routledge.

EACA: Ephorate of Antiquities of the City of Athens, Archives.

EACA (Ephorate of Antiquities of the City of Athens). (2016). The conservation and valorisation of the Horologion of Andronikos of Kyrrhos, in the archaeological site of the Roman Agora of Athens, Project Report NSRF 2007-2013. Athens: Greek Ministry of Culture and Sports [In Greek].

ECCO (European Confederation of Conservator-Restorers' Organisations). (2002). Professional Guidelines I. The Profession. Retrieved from http://www.ecco-eu.org/fileadmin/user_upload/ECCO_ professional_guidelines_I.pdf (Accessed 17/04/2018).

ECCO (2003). Professional Guidelines II. Code of Ethics. Retrieved from http://www.ecco-eu.org/ fileadmin/user_upload/ECCO_professional_guidelines_II.pdf; (Accessed 17/04/2018).

Georgaki, P. (2012). Restoration of ancient vases: questions of aesthetics and ethics from an international and Greek museum experience. Phil. Diss. Thessaloniki: Aristotle University of Thessaloniki [In Greek]. Hölling, H.B. (2017, September 4-8). Time and conservation. Paper presented at ICOM CC 18th Triennial Conference, Copenhagen. Paris: International Council of Museums. Retrieved from http://icom-cc-publications-online.org/PublicationDetail.aspx?cid=53384c17-3c46-4c24-8917650f145a5530.

Jones, H. (2002). The Importance of Being Less Earnest: Communicating Conservation. V\&A Conservation Journal, 41, 20-22. Retrieved from http://www.vam.ac.uk/_data/assets/pdf_ file/0004/177376/20027_file.pdf (Accessed 17/04/2018).

Jones, M. (1994). Why fakes? In S. Pearce (Ed.): Interpreting objects and collections (pp.92-97). London: Routledge. 
ICOMOS (International Council for Monuments and Sites). (1964). International Charter for the Conservation and Restoration of Monuments and Sites (the Venice Charter). Retrieved from https:// www.icomos.org/charters/venice_e.pdf (Accessed 17/04/2018).

ICOMOS (1994). Nara Document on Authenticity in Relation to the World Heritage Convention. Adopted in Nara Conference. Retrieved from https://www.icomos.org/charters/nara-e.pdf (Accessed 17/04/2018).

ICOMOS-ISCS (2008). Illustrated glossary on stone deterioration patterns. Retrieved from https:// www.icomos.org/publications/monuments_and_sites/15/pdf/Monuments_and_Sites_15_ISCS_ Glossary_Stone.pdf (Accessed 17/04/2018).

Kemp, J. (2009). Practical Ethics v2.0. In A. Richmond \& A. Bracker (Eds.), Conservation: principles, dilemmas and uncomfortable truths (pp. 60-72). London: Routledge.

Kienast, H. (2008). The Tower of the Winds in Athens. Athens: Archaeological Receipts Fund.

Kienast, J.H. (2013). The Tower of the Winds in Athens. The Australian Archaeological Institute at Athens (AAIA) Bulletin. 9, 20-29.

Marçal, H.P., Macedo R.A.S.P. \& Duarte, A.M.S.P. (2014, September 15-19). The inevitable subjective nature of conservation: Psychological insights on the process of decision making. Paper presented at ICOM-CC 17th Triennial Conference, Melbourne. Paris: International Council of Museums. Retrieved from http://icom-cc-publications-online.org/PublicationDetail.aspx?cid=c8677218-738b-4d1c-96305ed0ce8d84b4 (Accessed 17/04/2018).

Matero, F. (2000). Ethics and Policy in Conservation. Getty Conservation Institute Newsletter, 15, Number 1 Spring, 5-9. Retrieved from http://www.getty.edu/conservation/publications_resources/ newsletters/pdf/v15n1.pdf (Accessed 24/1/2018).

McClure, I. (2013). Making exhibitions of ourselves. In E. Williams (Ed.), The Public Face of Conservation (pp. 163-169). London: Archetype Publications.

Melucco Vaccaro, A. (1996). The emergence of modern conservation theory. In N. Stanley-Price, M. Kirby Talley \& A. Melucco Vaccaro (Eds.), Historical and Philosophical Issues in the Conservation of Cultural Heritage (pp. 202-211). Los Angeles: Getty Conservation Institute.

Mertzani, M. (2008). Issues of exhibiting, supporting and restoring sculpture. In P. Adam-Veleni \& D. Ignatiadou (Eds), Stone. Paper presented at Conservation Conference, Archaeological Museum of Thessaloniki, 2007 (pp. 89-103). Thessaloniki: ZHTH [In Greek].

Muñoz Viñas, S. (2005). Contemporary Theory of Conservation, Oxford: Elsevier ButterworthHeinemann.

Noble, J. \& de Solla Price, D. (1968). The water clock in the Tower of the Winds. American Journal of Archaeology, 72(4), 345-355.

Papadopoulou, M. (2017). The role of conservation in the interpretation of monuments and museum objects. Master Thesis. Athens: Panteion University of Social and Political Sciences [In Greek].

Papastamatiou, Kl. \& Fotopoulou, M. (2011). Horologion of Andronikos of Kyrrhos [Conservation Study]. Athens: Directorate of Conservation of Ancient and Modern Monuments [In Greek]. 
Philippot, P. (1996). Restoration from the perspective of the humanities. In N. Stanley-Price, M. Kirby Talley \& A. Melucco Vaccaro (Eds.), Historical and Philosophical Issues in the Conservation of Cultural Heritage (pp. 216-229). Los Angeles: Getty Conservation Institute.

Pye, E. (2001). Caring for the Past: Issues in Conservation for Archaeology and Museums, London: James and James.

Richmond, A. \& Bracker, A. (Eds.). (2009). Conservation: principles, dilemmas and uncomfortable truths. London: Routledge.

Robinson, H. (1943). The Tower of the Winds and the Roman Market-Place. American Journal of Archaeology, 47(3), 291-305.

Smith, Ch. S. (1989). Museums, artefacts and meanings. In P. Vergo (Ed.), The new museology (pp. 6-21). London: Reaction Books.

Spantidaki, G. (2005). Conservation: A privileged time for the study of archaeological textiles. Paper presented at Conservation and Display of Conserved Artefacts. Technical and Aesthetic Problems, Conference, Byzantine \& Christian Museum, Athens, 29/1/2003 (pp. 109-110). Athens: Byzantine \& Christian Museum [In Greek].

Tournikiotis, P. (2010). Ideological and theoretical problems of anastylosis of architectural monuments in Greece in the second half of the 20th century. In Chr. Bouras \& P. Tournikiotis (Eds.), Conservation, anastylosis and restoration of monuments in Greece 1950-2000 (pp. 13-28). Athens: Cultural Foundation of the Piraeus Bank Group [In Greek].

Villers, C. (2004). Post minimal intervention. The Conservator, 28, 3-10.

Walden, S. (1985). The ravished image: or how to ruin masterpieces by restoration. London: Weidenfeld and Nicholson.

Webb, P. (2017). The Tower of the Winds in Athens: Greeks, Romans, Christians, and Muslims: Two Millennia of Continual Use. Philadelphia, PA: American Philosophical Society.

Williams, E. (Ed.). (2013). The Public Face of Conservation. London: Archetype Publications.

(c) The copyright on the depicted monument belongs to the Greek Ministry of Culture \& Sports 
